Revista de Comunicación y Salud, 2020, Vol. 10, no 2, pp. 185-210

Editado por Cátedra de Comunicación y Salud

ISSN: 2173-1675

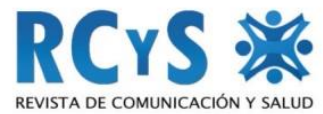

Enviado 15/08/2020

Aprobado 30/09/2020

\title{
ANÁLISIS DE CONTENIDO DE LA PRENSA DIARIA ESPAÑOLA SOBRE EL USO DE LA INFOGRAFÍA PARA INFORMAR DE LA CRISIS SANITARIA DE LA COVID-19
}

\section{Content analysis of the Spanish press about the use of the resource of infographics to report information regarding the global health crisis originated by COVID-19}

\author{
Guiomar Salvat Martinrey ${ }^{1}$ \\ Universidad Rey Juan Carlos. España. \\ quiomar.salvat@uric.es \\ Sara Aranda Martínez \\ Periodista y comunicadora audiovisual. España. \\ sar.arandam@gmail.com
}

\section{Resumen}

Este trabajo analiza las infografías publicadas en prensa durante los primeros meses de la pandemia para informar de la crisis sanitaria mundial que en 2020 provoca la covid19 con el objetivo de conocer el uso que se hace de este género periodístico así como las técnicas y elementos que tienen mayor presencia y que caracterizan la información relativa al coronavirus. Partimos de la hipótesis de que el género periodístico más adecuado para transmitir esta información compleja a una sociedad heterogénea es la infografía. Se ha realizado una investigación mediante la técnica de análisis de contenido para conocer el uso que la prensa española, concretamente El País, El Mundo, La Vanguardia y $A B C$, hace de los elementos infográficos en esta pandemia. Durante este periodo se evidencia el significativo incremento del número de infográficos en prensa utilizados para informar de la covid-19 y que los datos utilizados en un momento de alarma social requieren las fuentes de información gubernamentales. Con respecto a las técnicas más recurrentes son gráficas simples, ubicativas y códigos de color que garantizan una rápida comprensión para el conjunto de la población. Se consolida el diseño de la información de la pandemia en todas las cabeceras para fomentar la coherencia y continuidad en los estilos gráficos así como una eficaz gestión de los datos, que además permite el conocimiento previo del diseño y la técnica a los lectores.

1 Autora para correspondencia: Guiomar Salvat Martinrey, Universidad Rey Juan Carlos, guiomar.salvat@urjc.es. 
Análisis de contenido de la prensa diaria española sobre el uso de la infografía para informar de la crisis sanitaria de la COVID-19

Palabras clave: Covid-19; Información sanitaria; Información de crisis; Infografía; Visualización de datos; Periodismo de datos; Mapas; Gráficos; Fuentes de información; Visualización de información.

\begin{abstract}
This paper examines a series of infographics designed to share information regarding the global health crisis originated by COVID-19 in 2020 that were published in the press during the first months of the pandemic. This research aims to explore how infographics are used, as well as the most recurrent elements and techniques used in information related to COVID-19. Information produced by the media to cover different topics on the pandemic presents a challenge for journalism due to what has been categorized as complex information. Drawing on the hypothesis that infographics may be the most suitable journalistic genre to render complex information, we developed a research based on content analysis so as to determine the usage that four Spanish newspapers ( $E l$ País, El Mundo, La Vanguardia and $A B C$ ) make of infographics elements. During this period, we observe a significant increase in the number of infographics found in the press to report the pandemic. In addition, data used at a time of social alarm must be obtained from governmental information sources. Regarding the most recurrent techniques, we detect simple, locational graphics and color codes that ensure a quick understanding of information for all citizens. The design of information covering the pandemic is consolidated in all the headers to promote coherence and continuity in graphic styles, as well as effective data management, which also provides readers with prior knowledge of the design and technique. As a general conclusion, we consider that infographics are an essential genre in pandemic information due to the quantitative and locative nature of the information that shapes its graphic expression.
\end{abstract}

Keywords: COVID-19; Healthcare Information; Crisis Information; Infographics; Data visualization; Data journalism; Maps; Graphics; Information sources; Information display.

\title{
Cómo citar el artículo
}

Salvat Martinrey, G. y Aranda Martínez, S. (2020). Análisis de contenido de la prensa diaria española sobre el uso de la infografía para informar de la crisis sanitaria de la COVID-19. Revista de Comunicación y Salud, 10 (2), 185-210. doi: https://doi.org/10.35669/rcys.2020.10(2).185-210

\section{INTRODUCCIÓN}

En la actual crisis del coronavirus, y sus enormes consecuencias mundiales, informar a la sociedad se convierte en una necesidad de primer orden. Los medios informativos son los responsables de transmitir a la población tanto el desarrollo de la pandemia como todas las formas de actuación frente a la situación sanitaria de emergencia.

En la sociedad de la información en la que se ha desarrollado la crisis sanitaria por covid-19, las grandes cantidades de datos originados para el seguimiento y control de la 
Análisis de contenido de la prensa diaria española sobre el uso de la infografía para informar de la crisis sanitaria de la COVID-19

pandemia se han convertido en los protagonistas de la información que los medios trasladan al conjunto de la población. Los datos de las localizaciones, el seguimiento de las cifras de contagios y fallecidos, así como los macrodatos que informan sobre el impacto socioeconómico que ha generado la pandemia, han eclipsado el resto de la agenda temática. El periodismo de datos es la especialización encargada de la recogida, análisis e interpretación de los datos, utilizando para ello técnicas de visualización de datos. Para su difusión y publicación en los medios escritos la infografía es el elemento gráfico más indicado para transmitir esa información, haciéndola comprensible de forma rápida y visual a toda la población. Esto es lo que ha llevado a analizar el uso que los medios hacen de la infografía, ya considerada por la práctica totalidad de los expertos como un género periodístico, para informar durante esta crisis sanitaria.

\subsection{Hipótesis de trabajo}

Partimos de la hipótesis principal de que el género periodístico de la infografía es el más adecuado para transmitir la información compleja producida por la crisis mundial del coronavirus.

En segundo lugar, la profundización de la sociedad de la información con la ciencia de los datos ha cobrado un gran protagonismo y, por extensión, el periodismo de datos. Durante la crisis por coronavirus se lleva a cabo una sistemática recogida universal de datos tanto a nivel sanitario como económico, político y social, unos datos que además de ser objeto de análisis e investigación en sus ámbitos, son de interés mundial.

Por último, que los medios de comunicación son los responsables de difundir estos datos a toda la sociedad ávida de información por la alerta sanitaria. Las infografías se han convertido en el elemento informativo idóneo para representar estos datos por su rápida comprensión en la difusión de las informaciones al conjunto de la población.

\subsection{Objetivos de la investigación}

El objetivo general de esta investigación es realizar un análisis sobre el uso que los diarios hacen de las infografías para informar de realidades complejas acerca de la pandemia de la covid-19. Para ello se han estudiado los datos, las técnicas infográficas y las características de su publicación, para ver su influencia en el desarrollo formal de cada uno de los periódicos del estudio y la importancia que adquiere la infografía en la prensa española durante este periodo de crisis sanitaria.

Como objetivos secundarios establecemos:

- Conocer en qué medida la pandemia recurre al uso de la infografía así como su extensión y su aplicación como género periodístico que denota la calidad de las mismas.

- Acotar las técnicas y elementos infográficos que tienen mayor presencia y su relación con la naturaleza de los datos que caracterizan la información relativa al coronavirus. 
Análisis de contenido de la prensa diaria española sobre el uso de la infografía para informar de la crisis sanitaria de la COVID-19

- Con respecto a las técnicas infográficas se pretende conocer el estado actual en la prensa para ver cómo ha afectado la información de la pandemia en su uso.

- Determinar si hay un creciente interés y reconocimiento de la infografía como técnica informativa en esta crisis sanitaria en los medios informativos.

\section{ESTADO DE LA CUESTIÓN Y MARCO TEÓRICO}

Definimos infografía como el género periodístico que aúna el texto con otros lenguajes como la tipografía, el iconográfico, el color o la composición de los elementos para transmitir la información de manera acorde a la naturaleza de los datos que la conforman con el objetivo de una difusión eficaz, rápida y visual. Asumimos que la infografía es un género periodístico porque dispone de las técnicas concretas establecidas para la elaboración de la información, aunque participen diferentes lenguajes para su difusión en los medios, en tanto que, como información periodística, velará por la "veracidad, exactitud, claridad expositiva y rapidez de ejecución" (Alonso, 1998 , p. 1). Los lenguajes que participan posibilitan que la información aparezca ante los ojos del lector con claridad, sin olvidar que "la construcción gráfica es una disciplina que debe tener en cuenta, además de la técnica y de la intuición, los medios y las reglas de la semiología gráfica" (Cortizo Álvarez, 2007, p. 279).

Abreu Sojo recoge todo el argumentario que esgrimen diferentes autores para considerar la infografía un género periodístico y establece que la infografía "tiene una estructura claramente definida; tiene una finalidad; posee marcas formales que se repiten en diferentes trabajos; y tiene sentido por sí misma" (2002, p. 85). Todas y cada una de estas razones son suficientes por sí mismas para considerarlo como un género periodístico, y así se trata en este trabajo.

Esta aceptación de la infografía como género periodístico no se queda en el ámbito teórico sino que llega a infografistas como Alberto Cairo o Jaume Serra e incluso a los medios de información, como el diario El Mundo, que en su libro de estilo recoge que el desarrollo de los elementos infográficos, tanto a nivel técnico como informativo, ha sido tal que la infografía ha pasado a un primer plano hasta convertirse en "un género informativo aparte, diferenciado de la noticia escrita y de la ilustración, ya que es un compendio de técnicas tradicionalmente separadas -foto, gráfico por ordenador, datos escritos- que se unen inextricablemente para formar un conjunto periodístico diferenciado" (Diario El Mundo, s.f., p. 13).

Con respecto a las aportaciones de la infografía, Alberto Cairo (2012) se refiere a la ayuda que puede suponer para explicar los datos, especialmente numéricos, y lo que nos parece más interesante, es que en muchos casos recurrir a la infografía es la única manera que tienen los datos de ser comprendidos, ya que difundidos de otra manera a los lectores les resultarían invisibles. Las infografías por encima de todo deben regirse por el principio informativo y para ello los profesionales deben conocer su técnica y lenguajes y optar por las fórmulas gráficas que funcionan para un público lo más extenso posible sin caer en demostraciones artísticas por encima del criterio informativo. 
Análisis de contenido de la prensa diaria española sobre el uso de la infografía para informar de la crisis sanitaria de la COVID-19

El término visualización de datos lo consideramos análogo al de infografía y se utilizará igualmente en este trabajo porque entendemos que se refiere a los mismos procesos técnicos. Si bien es cierto que infografía tiene ciertas connotaciones en su difusión y es más propio del entorno del periodismo, y que la visualización de datos está asociado más al análisis científico de los datos y sobre todo a extensiones digitales de la infografía como el carácter dinámico y la interactividad, ambos comparten los principios esenciales. La cuestión relevante es tener siempre presente que "una cosa es la infografía general y otra la infografía informativa de prensa, que es un producto del infoperiodismo en cualquiera de los canales, soportes y procesos de fabricación" (Valero Sancho, 2000, p. 124).

Los datos informativos son la esencia de las infografías y por tanto de su calidad depende la información que vamos a obtener. A partir de ahí, el infografista construye la visualización de datos en base a los principios y técnicas. La visualización como herramienta busca, en primer lugar, comprender los datos obtenidos y, después, la representación más eficaz para su difusión en los medios de información.

Si algo ha caracterizado las fuentes de información durante la pandemia son los conflictos derivados de la mala recolección de los datos. Distintos sistemas, criterios y políticas han ofrecido datos que no concordaban en su conjunto, tanto a nivel nacional como internacional. La denuncia de esta situación entre administraciones, grupos políticos y la ciudadanía puso en evidencia la necesidad de una metodología de recogida sistemática, consensuada entre todas las localizaciones y basado en los mismos principios a nivel nacional. El descrédito y la fiabilidad de los datos encuentra un punto de cierto consenso cuando se estudian los muertos acaecidos en 2019 durante ese periodo y los de 2020 que evidencia el desfase de las cifras. La terrible diferencia entre ambas cifras se consideran muertes casi directas por covid-19 (Llanera, 2020).

Otra característica de los datos de la pandemia es que abarcan todos los ámbitos sociales, económicos y geopolíticos, y los periodistas se han enfrentado a una información compleja. La información de la pandemia enlaza mediante el virus infinidad de temáticas, características, factores y variables en unos datos complejos resultado de la unión de todo aquello que abarca, de manera mundial, a todas las culturas, economías, políticas y sociedades, convirtiéndolo en una situación informativa complicada.

Lo que pretenden las técnicas infográficas cuando se enfrentan a informaciones compuestas por elementos diversos, que a su vez pueden constituir una unidad o conjunto entre sí, es poder representarla sin ese carácter enmarañado o difícil para transmitirla de manera eficaz. Es decir, que estaríamos creando un sistema complejo, basados en principios muy simples, que nos permitirían comprender la información rápidamente y sin tener cualificación específica para ello. Y en ese sentido la infografía "transmite la información con el objetivo de aclarar lo complejo que difícilmente puede ser presentado por otros medios, como por ejemplo, proporciones y tendencias estadísticas, procesos complejos o mapas" (Cairo, 2012). La manera de comunicar

Revista de Comunicación y Salud, 2020, Vol. 10, nº 2, pp. 185-210 
Análisis de contenido de la prensa diaria española sobre el uso de la infografía para informar de la crisis sanitaria de la COVID-19

información compleja para los medios de información es ponerse en lugar del lector del medio, algo que resulta muy difícil cuando la sobreinformación caracteriza la complejidad. El periodista debe tener la capacidad de abstraerse de todo lo secundario ante tantos factores en los procesos informativos. Entonces tomamos conciencia de que "a medida que la información se vuelve más compleja, el diseño toma más importancia no sólo como contenedor de la noticia, sino como contenido informativo por sí mismo" (Subiela Hernández, 2017, p. 1022).

El desarrollo del Big Data o macrodatos entendido como el "conjunto de tecnologías, algoritmos y sistemas empleados para recolectar datos a una escala y variedad no alcanzada hasta ahora y a la extracción de información de valor mediante sistemas analíticos avanzados soportados por computación en paralelo" (Aced, Heras y Sáiz, 2017, p. 3) modifica el alcance de la información. El Big Data se caracteriza en el inicio por las denominadas 3 Vs: volumen, variedad y velocidad (Camargo-Vega et al., 2015), a las que se van agregando otras "para definir de forma más precisa al Big Data, por ejemplo, Veracidad (la calidad de los datos capturados es clave), Variabilidad (el significado de los datos cambia frecuentemente y se pueden producir inconsistencias que se han de manejar) y Valor (los ingresos o beneficios del Big Data)" (Aced, Heras y Sáiz, 2017, p. 3).

Estos datos masivos exigen una nueva especialización periodística, el periodismo de datos. El tratamiento y la difusión de esos datos requieren "del uso de herramientas tecnológicas y recursos disponibles en la red, de lenguajes de codificación y programación de algoritmos, de técnicas de procesamiento de datos masivos (macrodatos) y de conocimientos avanzados de la ciencia computacional (informática), al mismo tiempo más accesible y más asequible" (Flores Vivar y López López, 2020, p.81). La visualización de datos es una parte fundamental del análisis del Big Data y, como medio de representación para la difusión de los datos, se considera el producto por excelencia del periodismo de datos (Ferreras Rodríguez, 2016).

En los últimos treinta años han proliferado las infografías gracias a la digitalización de los procesos. Lo cierto es que desde el punto de vista de las funciones periodísticas no son tan novedosas. Desde la antigüedad existen formas gráficas complejas para representar información pero tenemos que esperar hasta 1638 para encontrar el "Prodigioso volcán" la primera infografía publicada en prensa (Tascón, 2011). Los mapas son las primeras infografías que se incluyen en la prensa diaria según Gonzalo Peltzer y explica como el mapa "expresa algunas o todas las componentes de una información de acuerdo con un orden geográfico" (1991, p. 140) aunque los mapas más elementales responden solo a la función de la localización.

Los gráficos y diagramas tampoco son novedad en lo esencial de la técnica infográfica, establecidas por William Playfair en The Commercial and Political Atlas en 1786, donde sienta las bases de las gráficas más utilizadas en la prensa y en sus palabras "sirve para simplificar lo complejo, permite al cerebro una mayor retención y es un instrumento visual de ayuda a hombres ocupados. Por último, los gráficos nos permiten ver relaciones aparentemente inexistentes entre variables, que suelen quedar

Revista de Comunicación y Salud, 2020, Vol. 10, nº 2, pp. 185-210 
Análisis de contenido de la prensa diaria española sobre el uso de la infografía para informar de la crisis sanitaria de la COVID-19

ocultas entre la multitud de datos y cifras, de difícil comparación de otro modo" (Playfair, s.f.) donde vemos que el planteamiento es absolutamente actual.

Lo que es nuevo es el uso que hacemos de la infografía cada vez que nos enfrentamos a una situación informativa no cotidiana, lo que supone plantearse cuál es la aplicación adecuada en la situación que se vive. En este momento la digitalización acelera y amplía los procesos de la visualización de datos, con la capacidad de asociar a los gráficos fuentes de información procedentes del Big Data. Se dispone de un amplio repertorio de programas que generan de manera automatizada y en línea mapas y gráficas realmente complejas, tanto técnica como informativamente, en cuestión de minutos. Eso sí es novedoso, y es todo lo que se ha utilizado para tratar la información compleja acerca de la pandemia.

Si nos alejamos de nuestro objeto de estudio para observar en su conjunto el diseño de la información periodística, en el que la infografía es un campo específico, podemos constatar cómo la infografía genera sinergias con el conjunto de las informaciones puestas en página y viceversa, aunque cada uno tenga su propio lenguaje visual. Analizar el uso de las técnicas infográficas requiere esa visión de conjunto con todas las jerarquías en las páginas, secciones y la publicación (Salvat, 2003). Aunque los manuales de estilo a veces separen lo que corresponde a la maquetación y el diseño de sus páginas de lo referente a la infografía, ambas áreas se definen en función de la otra. De hecho, algunas de las funciones de las maquetaciones requieren elementos iconográficos como pictogramas o grafismos, que no alcanzan a ser infografías como género periodístico, pero que asisten y son fundamentales para organizar, jerarquizar y presentar la información, las tres funciones que definen el diseño periodístico. La tendencia de su uso cada vez es mayor por la necesidad de estructurar las páginas y secciones acorde a los nuevos medios digitales que fomentan el despiece de las informaciones en unidades menores permitiendo la agilidad de la lectura, la selección de los contenidos y facilitando los distintos niveles de lectura.

Las infografías en los medios suelen ir asociadas a las informaciones más relevantes de actualidad y normalmente aparecen los días siguientes al desarrollo de grandes acontecimientos. "Cada vez que un conflicto bélico u otro acontecimiento excepcional salta a la actualidad: los gráficos crecen en tamaño y en protagonismo" (Hernández Lorca, 2010, p.83) atendiendo a diferentes razones, ya sean prácticas o informativas.

Durante una crisis o cambio profundo y de consecuencias importantes la información cobra todo el protagonismo de la vida social y entonces la infografía de prensa se utiliza para informar de eventos de gran urgencia como guerras, atentados, accidentes o catástrofes (Valero Sancho, 2008). Las grandes catástrofes y crisis globales generan información de interés universal. El año 1991 es el año de referencia para la infografía española. La Primera Guerra del Golfo supuso para los diarios españoles del momento un enorme esfuerzo de cobertura, no solo para la sección de internacional, sino también para las secciones de infografismos (Serra, 1998). Los diarios El Sol, El Mundo, La Vanguardia, El Periódico, $A B C$ y El País, entre otros, informaron diariamente a través de infografías de los grandes combates de la jornada anterior (Serra, 1998). Las

Revista de Comunicación y Salud, 2020, Vol. 10, nº 2, pp. 185-210 
Análisis de contenido de la prensa diaria española sobre el uso de la infografía para informar de la crisis sanitaria de la COVID-19

infografías cumplieron un papel fundamental, sobre todo, por la falta de acceso a fotografías (Hernández-Lorca, 2010). Algo similar ocurrió con la cobertura de la guerra de las Malvinas (1982), la guerra Irán-Irak o la de los Balcanes (1991-2001). El uso de infografías en este tipo de acontecimientos permite "la visión de múltiples lugares y facetas diversas así como tiempos sucesivos para mostrarlos a lo largo de los días, yendo de más a menos" (Valero Sancho, 2008, p.637).

La epidemia mundial por coronavirus es una nueva realidad a la que todo el mundo se ha tenido que enfrentar. En esta crisis "se aprecia tanto el factor sorpresa como la desestabilización, el estrés y la reducción de los tiempos que condiciona la toma de decisiones, la emoción de los públicos afectados, la presión mediática, el desafío para la imagen de las autoridades y el peligro para la posición de poder de los gobernantes" (Crespo y Garrido, 2020, p.13). Los medios de información se han visto condicionados porque la alarma y la preocupación por la extensión del virus ha superado las barreras nacionales antes incluso de que llegaran a tomarse medidas internas en los países.

Covid-19 es el nombre que la OMS ha dado a "la enfermedad infecciosa causada por el coronavirus" descubierto en Wuhan, China. Este virus recibe el nombre científico de coronavirus SARS-CoV-2, y provoca su primera víctima mortal el 9 de enero de 2020, en China. Pronto se extiende a Tailandia y Japón. El 21 de enero, Estados Unidos confirma un primer contagio en el país, el primero del continente americano. Un día después, la ciudad de Wuhan cierra sus aeropuertos y estaciones de tren y China confirma 547 infectados y 17 fallecidos en el país (ACNUR, 2020). El 24 de enero se detectan en Francia los primeros casos de Europa. El 30 de enero la OMS presenta un informe de situación en el que se recoge que hay un total de 7.818 casos confirmados en todo el mundo y se declara la situación de emergencia internacional de salud pública. El 11 de marzo se pasa a considerar la situación como pandemia, entendida como la "propagación mundial de una nueva enfermedad" (OMS, 2020).

El primer caso de covid-19 confirmado en España se da el 31 de enero de 2020, un turista alemán residente en la isla de La Gomera (ACNUR, 2020), fecha relevante en nuestra cronología para iniciar el estudio. El 4 de marzo se confirma la primera víctima mortal en España y empiezan a plantearse las primeras medidas de distanciamiento social (Marca, 2020) aunque continúan celebrándose actos multitudinarios que se convierten en los principales focos del virus. Cuando el 11 de marzo la OMS declara la situación de pandemia mundial, en España se registran unas cifras de 2.218 personas contagiadas y 54 fallecidos (Marca, 2020). Al día siguiente el Gobierno decide cerrar todos los centros educativos de España, para un día más tarde decretar el estado de alarma. En ese momento, el número de contagios asciende a 5.200 y los fallecidos superan los 133.

El 24 de marzo España se posiciona por delante de China en número de contagios y cuatro días después, el Gobierno decide suspender todas las actividades no esenciales. El 1 de abril el número de infectados en España supera los 100 mil y el número de fallecidos los 9 mil (ACNUR, 2020) así que el día 3 se establece una nueva prórroga del 
Análisis de contenido de la prensa diaria española sobre el uso de la infografía para informar de la crisis sanitaria de la COVID-19

estado de alarma y se empiezan a preparar zonas de cuarentena para los contagiados asintomáticos.

A partir del día 10 de abril la cifra de fallecidos diarios baja paulatinamente y el 22 de abril, tras acordar otra prórroga, el Gobierno anuncia una desescalada gradual de las medidas de restricción. El 28 de abril se anuncian las medidas para el fin del confinamiento y al día siguiente se presenta el plan, establecido en 4 fases de desescalada. El número de muertes registradas hasta el momento es de 23.882 , de 210.773 los casos de contagio y 102.548 los casos de personas contagiadas recuperadas (RTVE, 2020). Esta es una breve cronología de la emergencia sanitaria en la que se encuadra nuestra investigación.

\section{METODOLOGÍA}

La metodología escogida para esta investigación es el análisis de contenido, siendo objeto de estudio las infografías sobre la crisis mundial por coronavirus publicadas en diarios españoles de información general. El análisis de contenido es definido por Juan José Igartua como "cualquier procedimiento sistemático ideado para examinar el contenido de una información archivada" (2006, p.181). Esta técnica de investigación tiene como objetivo "obtener un resumen de las características de un conjunto de mensajes" (Igartua, 2006, p.184). Se ha seleccionado este procedimiento de investigación por su "idoneidad como técnica cuya utilización permite evaluar de forma empírica las características del mensaje informativo y a partir de ello obtener datos objetivos y significativos sobre el mismo" (López del Ramo y Humanes, 2016, p.90). Krippendorff recoge que una de las características del análisis de contenido es su fiabilidad, debido a que "si otros investigadores, en distintos momentos y quizás en diferentes circunstancias, aplican la misma técnica a los mismos datos, sus resultados deben ser los mismos que se obtuvieron originalmente" (1990, p.29).

El corpus o muestra de la investigación son las infografías que los diarios nacionales de información general El País, El Mundo, La Vanguardia y $A B C$ publican, en su versión impresa, sobre la crisis mundial de coronavirus. Según los resultados de la Primera Ola de 2020 del Estudio General de Medios (EGM) estos diarios son los que tienen un mayor número de lectores. Así, El País se posiciona como el diario generalista con más lectores al día y alcanza la cifra de 1.044.000, seguido de El Mundo con 657.000 lectores, La Vanguardia con 532.000 y cuarto lugar el diario $A B C$ con 444.000 lectores al día.

El periodo de análisis elegido para esta investigación abarca desde el 31 de enero, cuando se detecta el primer caso de coronavirus en España, hasta el 29 de abril de 2020, fecha en la que el Gobierno anuncia el comienzo de la desescalada para poner fin a la cuarentena en la que los españoles se encontraban desde el 14 de marzo de 2020.

De la muestra definida han resultado un total de 360 publicaciones diarias, 90 por cada una de las cuatro cabeceras seleccionadas para la investigación. El análisis de los

Revista de Comunicación y Salud, 2020, Vol. 10, nº 2, pp. 185-210 
Análisis de contenido de la prensa diaria española sobre el uso de la infografía para informar de la crisis sanitaria de la COVID-19

diarios se ha realizado al completo, teniendo en cuenta todas las secciones y páginas de cada uno de ellos. El número de unidades de estudio obtenido, es decir, todas las infografías publicadas por El País, El Mundo, La Vanguardia y $A B C$, ha sido de 1.123 en este periodo. Se han contabilizado todos los elementos infográficos sin importar su temática, salvo los mapas del tiempo, que se han descartado del cómputo.

Para llevar a cabo el análisis de contenido se ha desarrollado un libro de código con 18 variables abstractas y sus respectivos valores. Entendiendo las variables como "atributos, cualidades, características observables" (Ñaupas Paitán et al., 2014, p.186) y las variables abstractas como aquellas que no son directamente observables 0 cuantificables, y necesitan una definición precisa para que sea posible su medición. Como unidad de estudio se ha definido cada una de las infografías publicadas en los diarios seleccionados durante el 31 de enero y el 29 de abril de 2020. Se han tenido en cuenta todas las infografías publicadas para finalmente establecer como unidad de análisis las que versan sobre la temática de la pandemia por coronavirus. Es por esto por lo que se han analizado los ejemplares al completo, siendo un total de 360 .

Tabla 1. Variables abstractas establecidas para el análisis de contenido.

\begin{tabular}{|c|c|c|}
\hline & VARIABLES & VALORES \\
\hline 1 & Diario & $\begin{array}{ll}\text { 1. } & \text { El País } \\
\text { 2. } & \text { El Mundo } \\
\text { 3. } & \text { La Vanguardia } \\
\text { 4. } & A B C\end{array}$ \\
\hline 2 & Fecha & Del 31 de enero de 2020 al 29 de abril de 2020 \\
\hline 3 & Temática coronavirus & $\begin{array}{ll}\text { 1. } & \text { Sí } \\
\text { 2. } & \text { No }\end{array}$ \\
\hline 4 & Sección & $\begin{array}{ll}\text { 1. } & \text { Portada } \\
\text { 2. Internacional } \\
\text { 3. Opinión } \\
\text { 4. España } \\
\text { 5. Sociedad } \\
\text { 6. Economía } \\
\text { 7. Ciencia } \\
\text { 8. Tecnología } \\
\text { 9. Cultura } \\
\text { 10. Deportes } \\
\text { 11. Local } \\
\text { 12. Salud } \\
\text { 13. En Portada } \\
\text { 14. Especial coronavirus } \\
\text { 15. Tendencias } \\
\text { 16. Política } \\
\text { 17. Contraportada }\end{array}$ \\
\hline
\end{tabular}


Análisis de contenido de la prensa diaria española sobre el uso de la infografía para informar de la crisis sanitaria de la COVID-19

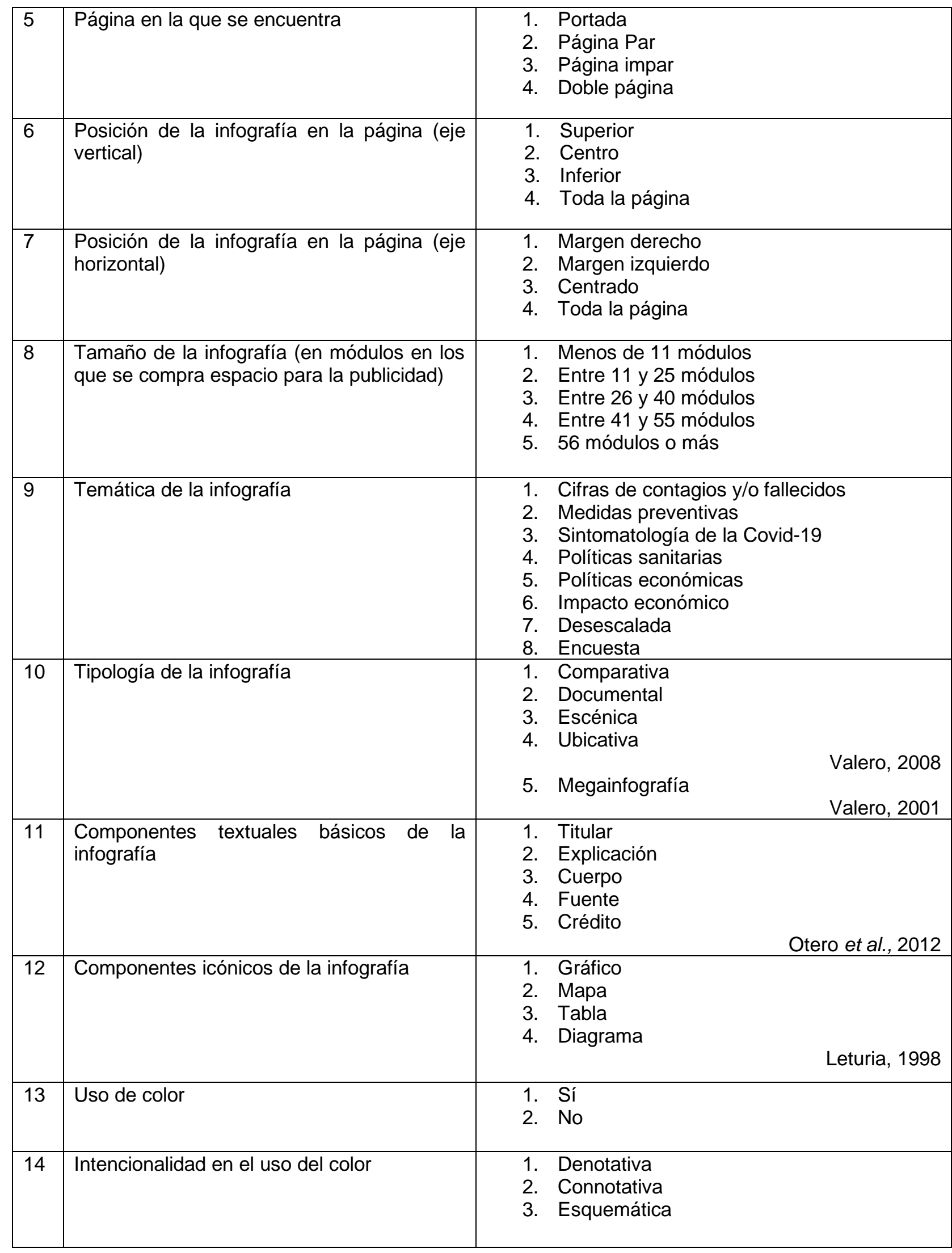


Análisis de contenido de la prensa diaria española sobre el uso de la infografía para informar de la crisis sanitaria de la COVID-19

\begin{tabular}{|c|c|c|}
\hline 15 & $\begin{array}{l}\text { Funcionalidad del color en los elementos } \\
\text { infográficos }\end{array}$ & $\begin{array}{ll}\text { 1. } & \text { Informativa } \\
\text { 2. } & \text { Compositiva } \\
\text { 3. } & \text { Connotativa } \\
\text { 4. } & \text { Simbólica }\end{array}$ \\
\hline 16 & Origen de la información (fuente) & $\begin{array}{ll}\text { 1. } & \text { Organismo público } \\
\text { 2. Empresa privada } \\
\text { 3. } \\
\text { 4. } \\
\text { 5. } & \text { Exopio de comunicación } \\
\text { 5. } & \text { Experto }\end{array}$ \\
\hline 17 & Elaboración & $\begin{array}{ll}\text { 1. } & \text { Propia } \\
\text { 2. } & \text { Experto } \\
\text { 3. } & \text { Medio de comunicación } \\
\text { 4. } & \text { Empresa privada } \\
\text { 5. } & \text { Organismo público }\end{array}$ \\
\hline 18 & Relación con el texto & $\begin{array}{l}\text { 1. Infografía informativa independiente } \\
\text { 2. Infografía complementaria }\end{array}$ \\
\hline
\end{tabular}

Fuente: Elaboración propia.

\section{DISCUSIÓN}

El uso de infografías aumenta progresivamente al ritmo en que se profundiza la crisis sanitaria y se evidencia que es la pandemia la responsable de este aumento infográfico cuando analizamos las temáticas. Del total de las 1.123 unidades contabilizadas en el estudio, el diario La Vanguardia es el que más infografías publica de cualquier temática con un 33,9\%, mientras que el diario El País alcanza el 18,5\%, el 20,5\% por El Mundo, y el $26,9 \%$ por $A B C$.

Pero si nos fijamos en las infografías cuya temática específica es la pandemia y que, por tanto, han constituido las unidades de análisis, un total de 583, las infografías publicadas por La Vanguardia ascienden al $51,9 \%$ del total de las publicadas, siendo de nuevo el diario que más infografías relacionadas con la covid-19 publicó distribuidos de la siguiente temporalmente de esta manera: 
Análisis de contenido de la prensa diaria española sobre el uso de la infografía para informar de la crisis sanitaria de la COVID-19

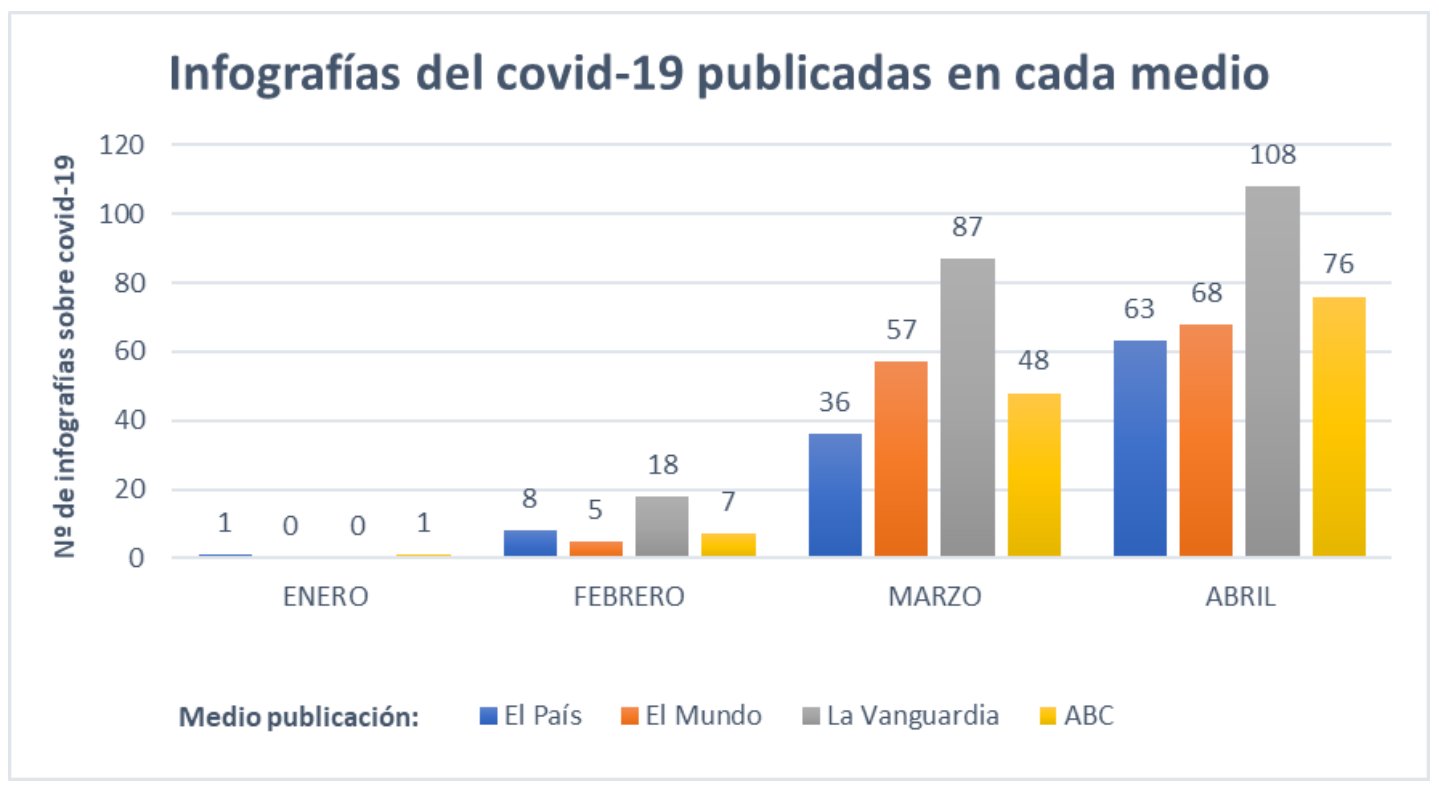

Gráfico 1. Infografías del coronavirus publicadas por meses en cada diario.

Fuente: Elaboración propia.

Por tanto, la tendencia en la publicación de infografías específicas es ascendente a medida que la crisis sanitaria se agrava y se consolida un uso mayor de infográficos, llegando en el mes de abril a publicarse 315 infografías, lo que supone el 54\% del total de las específicas.

Para determinar el uso informativo que se hace de la infografía nos centramos en las variables del espacio físico que ocupan en la página, contabilizado en módulos, y la construcción de infografías completas e independientes propias del género periodístico, ya que ambas determinan la calidad de los infográficos referentes a la pandemia.

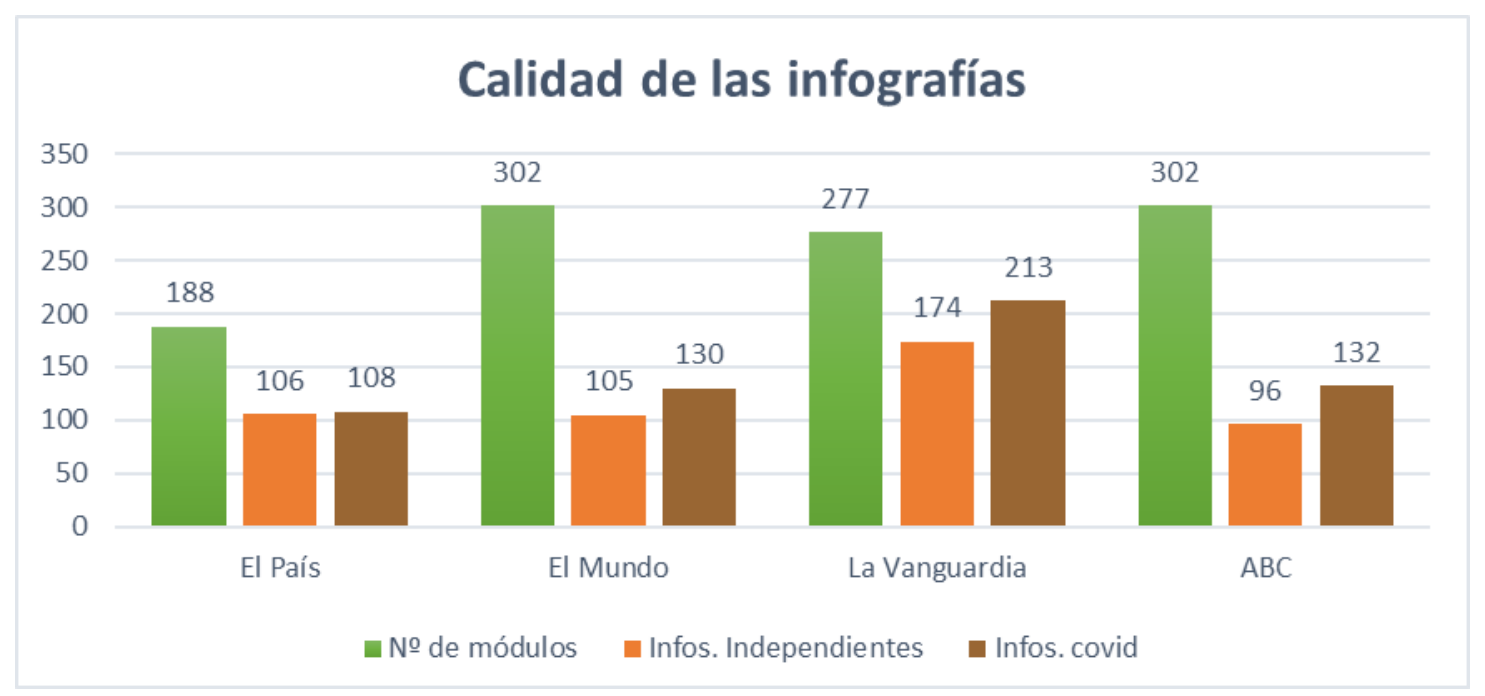

Gráfico 2. Infografías del coronavirus publicadas, el espacio que ocupan en módulos y las que funcionan como género periodístico independiente.

Fuente: Elaboración propia.

Revista de Comunicación y Salud, 2020, Vol. 10, nº 2, pp. 185-210 
Análisis de contenido de la prensa diaria española sobre el uso de la infografía para informar de la crisis sanitaria de la COVID-19

Lo sorprendente de la gráfica es que no es cuestión de la cantidad de infografías, que también, sino de la dedicación de tiempo y recursos para dedicarles un espacio y afán informativo por parte de las cabeceras. Así se evidencia en las publicaciones de El País, que con un número menor de los elementos infográficos publicados, optan por infografías completas que funcionan como género periodístico independiente en un $98.1 \%$, mientras que La Vanguardia, con un número elevado de infografías, en realidad resuelve en muy poco espacio la mayoría de las veces y dedica menos espacio que El Mundo y $A B C$, que tienen casi la mitad de infografías, y dedican el doble de espacio a las publicadas evidenciando una mayor calidad.

Las enormes consecuencias sociales, fundamentalmente de salud, de la epidemia determinan que la mayor parte de las infografías, el 42,3\%, se publiquen en la sección de Sociedad. Por otra parte, en contra de nuestros pronósticos, en la sección de Internacional sólo se concentra el 8,7\% de las infografías de la covid-19 pese al carácter universal de la pandemia, tanto por la extensión como las repercusiones que tiene cada foco de contagio en los demás países. Resulta interesante la presencia de infografías en las secciones de Política y Opinión, donde no son habituales, pero sí muy pertinente la apertura a este género periodístico, a partir del cual se debate, analiza u opina. Ensombrece esta pequeña euforia en el imperio de la infografía la poca presencia que tiene en la Primera página de los diarios la infografía de la pandemia, ya que tan solo representa un $0,8 \%$ del total de las infografías destacando que El País lleva tres a portada y el resto de las cabeceras solo una.

Se quería conocer el grado de producción que tenían las secciones de infografía y si cuentan con recursos suficientes para publicar sus propias visualizaciones o bien participan otros agentes. De los valores observados, establecidos en la variable 17, se evidencia que son elaboradas en su inmensa mayoría por los departamentos infográficos de cada una de las cabeceras que se han analizado, salvo alguna colaboración de expertos y únicamente una realizada por una empresa privada externa.

Con respecto a las temáticas específicas sobre las que tratan las infografías sobre el coronavirus mostramos los resultados que corresponden al total de los diarios debido al consenso entre las cabeceras. Prevalece la cifra de contagios y/o fallecidos, con una media entre todos los diarios del $55,4 \%$, siendo estos datos recogidos y publicados cada día por todas las cabeceras entendido como la evidencia del avance o retroceso del virus. 
Análisis de contenido de la prensa diaria española sobre el uso de la infografía para informar de la crisis sanitaria de la COVID-19

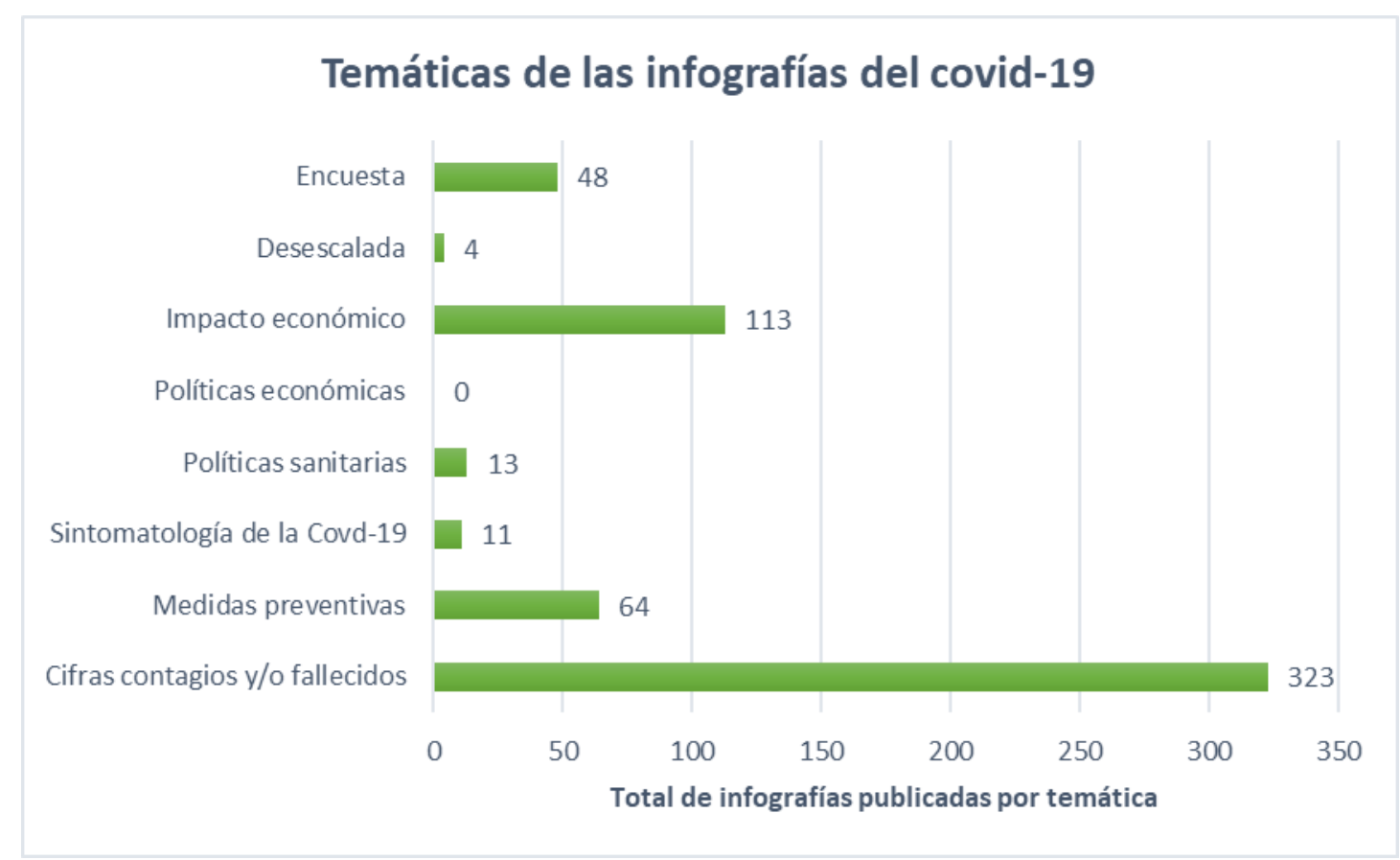

Gráfico 3. Temáticas de la pandemia de las infografías publicadas en todas las cabeceras del estudio.

Fuente: Elaboración propia.

Consideramos que conocer las fuentes de información utilizadas para representar los datos es significativo en el estudio ya que determinan la fiabilidad de los mismos y el peso y la confianza que se deposita en los organismos públicos. El resultado es que el $40,1 \%$ de las infografías publicadas por los diarios seleccionados hace uso de datos de organismo públicos en exclusiva para su elaboración, siendo por tanto la fuente más utilizada. La extensión del problema y la capacidad de recogida justifican los datos, y a pesar de todo nos parece un porcentaje bajo para las responsabilidades que tienen los organismos oficiales nacionales e internacionales en el desarrollo de la pandemia. La segunda fuente más recurrida ha sido la de empresas privadas con un $23,4 \%$, pero en muchos casos no se ha utilizado como única sino como complemento de las fuentes públicas. También se han consultado datos de otros medios de comunicación para elaborar las infografías con una media entre todos los diarios $4,2 \%$ y las que utilizan información propia apenas alcanza el 6,3\% lo que evidencia la poca capacidad de las publicaciones para conseguirlos, pero dada la naturaleza de la crisis, se entiende.

Para conocer las técnicas infográficas utilizadas con objeto de cubrir el tema de la pandemia nos acercamos a los componentes icónicos de la infografía desde la catalogación que Leturia (1998) establece y que diferencia entre gráficos, mapas, tablas y diagramas. Así el $53,3 \%$ de las unidades de análisis estaban compuestas exclusivamente por gráficos, un $12,1 \%$ son infografías que combinan gráficos y mapas y $8,4 \%$ que se componen solo de mapas. Cabe destacar el número de infografías que tanto en El Mundo con un $4,1 \%$ como $A B C$ con un $5,6 \%$ se componen de gráficos, mapas y tablas. Estos resultados evidencian la concordancia de su representación con 
Análisis de contenido de la prensa diaria española sobre el uso de la infografía para informar de la crisis sanitaria de la COVID-19

los datos de la información: en primer lugar, son cantidades comparativas (recordemos que la cifra de contagios/fallecido es la más recurrente) y se han expresado casi siempre en gráficos de columna o de fiebre y la importancia del referente espacial de los datos durante toda la pandemia por la importancia de la localización de la información que se concreta en los mapas. Es evidente que este tipo de gráficas son las más utilizadas junto con los mapas, no solo de manera independiente, sino en infografías mixtas que aúnan ambas técnicas.

Establecer unas categorías atendiendo a la utilidad de la infografía en el proceso informativo es fundamental para el estudio y no basamos en las que establece Valero Sancho (2008) que diferencia cuatro tipos de infografías, a las que decidimos incorporar la megainfografía como otra modalidad para especificar dentro de las infografías informativas y que "son las que cubren la totalidad de la información existente sobre un acontecimiento, acción o cosa, a una o más páginas" (Valero Sancho: 2001, p. 83).

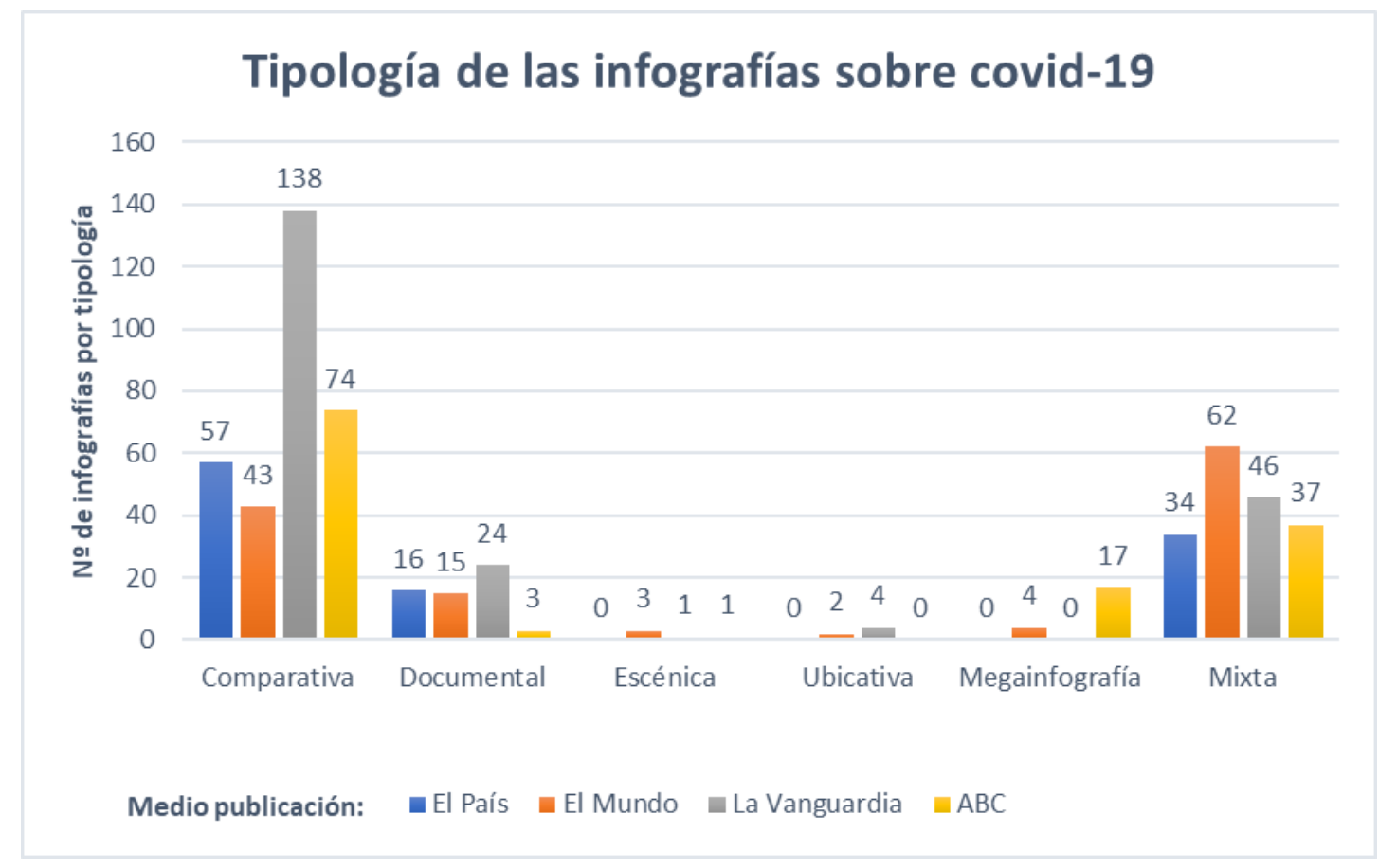

Gráfico 4. Número de infografías publicadas por medio según la función que desempeñan.

Fuente: Elaboración propia.

Respecto a la tipología de las infografías analizada, de los $53,5 \%$ presentaban una tipología comparativa, el 9,9\% documental, un 0,8 escénica y el 1\% ubicativa. Además se han analizado los elementos que informaron a través de una tipología mixta en un $30,7 \%$, comparativa y ubicativa, siendo estas dos funciones el paradigma de la información del covid-19. Se localizaron un total de 23 megainfografías, todas ellas relacionadas con la temática de esta investigación dejando en evidencia el interés informativo. El diario $A B C$ fue el que más publicó, un total de 17, seguido de El Mundo y 
Análisis de contenido de la prensa diaria española sobre el uso de la infografía para informar de la crisis sanitaria de la COVID-19

El País. El diario La Vanguardia fue el único que no hizo uso de megainfografías para informar.

Para atender a la intencionalidad en el uso de color de las infografías se recurre a las categorías tradicionales que diferencian entre Denotativa, cuando está vinculado al mundo de la representación de la realidad y el color se convierte así en un atributo realista o natural de los objetos o figuras; la Connotativa, si se representa el mundo de las sensaciones ya que la connotación es la acción de factores que no son descriptivos, sino psicológicos, simbólicos o estéticos; o bien la Esquemática, en caso de que haga referencia a los códigos de funcionalidad, arbitrariedad y espontaneidad. En este caso siempre se utiliza como color plano. El color es el lenguaje que está presente en todas y cada una de las infografías del estudio, y la intencionalidad predominante en su uso es la connotativa en un $90,7 \%$ de las infografías, seguida de la denotativa con un $9 \%$ mientras que la intencionalidad esquemática solo se ve representada en dos del total de las unidades de análisis.

En lo que respecta a la función que desempeña el color podemos hablar de categoría Informativa cuando el color de las imágenes posibilita un mejor conocimiento de la realidad $u$ objeto de referencia o favorece la comprensión del mensaje, de Compositiva cuando incide el color en el diseño con algunas de las seis variables compositivas, respecto a la que intenta que el color evoque emociones sería Connotativa y en el caso de una sintonía entre la temática y los colores de la página. Por último, en la función simbólicas se entiende cuando en la composición aparece alguna combinación cromática que se asocia con cualquier símbolo: bandera, escudo, logotipo, etcétera" (Montes Vozmediano y García Jiménez, 2015, p.123-124). En el estudio domina la función informativa con un $53,5 \%$ de las infografías analizadas seguida de la funcionalidad compositiva en un $41,6 \%$, la connotativa en el $2,4 \%$ de los casos y la simbólica tan solo en el 0,3\%. En un $2 \%$ de las infografías analizadas se ha combinado la funcionalidad informativa y compositiva del color. Esto nos lleva a considerar el uso del color como eficaz con los datos y con el diseño de la información.

Por último, queremos destacar un resultado común a la publicación, los datos y los elementos icónicos, y es que se ha generado y consolidado un diseño de la información específico durante la crisis del coronavirus. Son tres los factores que lo han determinado: en primer lugar, la duración de la pandemia en el tiempo que informativamente denota consolidación de un tema, en segundo lugar el "éxito" informativo por la demanda social que desea consultar directamente este tema de manera reconocible y en tercer lugar, la necesidad de crear una estructura previa que permita actualizar las informaciones de manera eficaz. Como resultado, diseños sólidos en todas las cabeceras que refuerzan la identidad de la temática y el medio.

Las características de los diseños de la información de la pandemia son que se diferencia la temática del resto de las secciones y se aúna creando un conjunto agrupando los contenidos. La coherencia de los diseños es más estricta y específica del tema en todos los órdenes gráficos que redunda en la facilidad de actualizar las gráficas 
Análisis de contenido de la prensa diaria española sobre el uso de la infografía para informar de la crisis sanitaria de la COVID-19

de acuerdo con esa continuidad que caracterizaba a los datos y que van componiendo la información día tras día, en muchos casos, de manera acumulativa.

En las cuatro cabeceras se cumple que, a partir de determinada fecha, el diseño de sus elementos infográficos se consolida. La información se actualiza y, en ocasiones, se modifica su posición en la página, pero no su diseño. Pero va más allá de los infográficos, y la visualización de la información se consolida dentro del marco de página conformando un todo coherente. Por tanto, que a cada tipo de información le corresponde siempre la misma representación consiguiendo de este modo, la concordancia a nivel de página y del medio en todas sus ediciones.

Para esta sinergia se utilizan los cintillos, los elementos tipográficos breves que enmarcan una serie de informaciones bajo un criterio temático con afán de contextualizar y unificar, con símbolos e iconos relativos al tema para facilitar y aumentar su eficacia de manera habitual. Pero también tienen presencia como elementos de localización espacial, temáticos y temporales en los despieces de información y cualquier texto de la página. Ejercen otra función, no informativa, cuando asisten a la maquetación para una mejor distribución de los textos, con alivios gráficos y distribuciones más efectivas donde en algunos casos los recorridos del texto se llevan a cabo con estos pictogramas. En definitiva, estas infografías menores son importantes en el diseño de la información para la organización y contextualización de las informaciones.

En el caso de El País, esto ocurre a partir del día 14 de abril y se caracteriza por mantenerse como un especial dentro de la sección de Sociedad. Se identifica por un cintillo que ubicado desde el lomo con el texto La crisis del coronavirus, por el diseño y la gama de color rojo que se mantiene en todos los mapas de puntos proporcionales y gráficos, por la ubicación en la parte superior de la página los pesos de la infografía y la repetición de los modelos a 5 y 3 columnas de la distribución de las infografías, con lo que se obtiene un modelo horizontal y otro vertical de página que se alternan según las necesidades informativas, dominando el vertical al centro o al interior de las páginas.
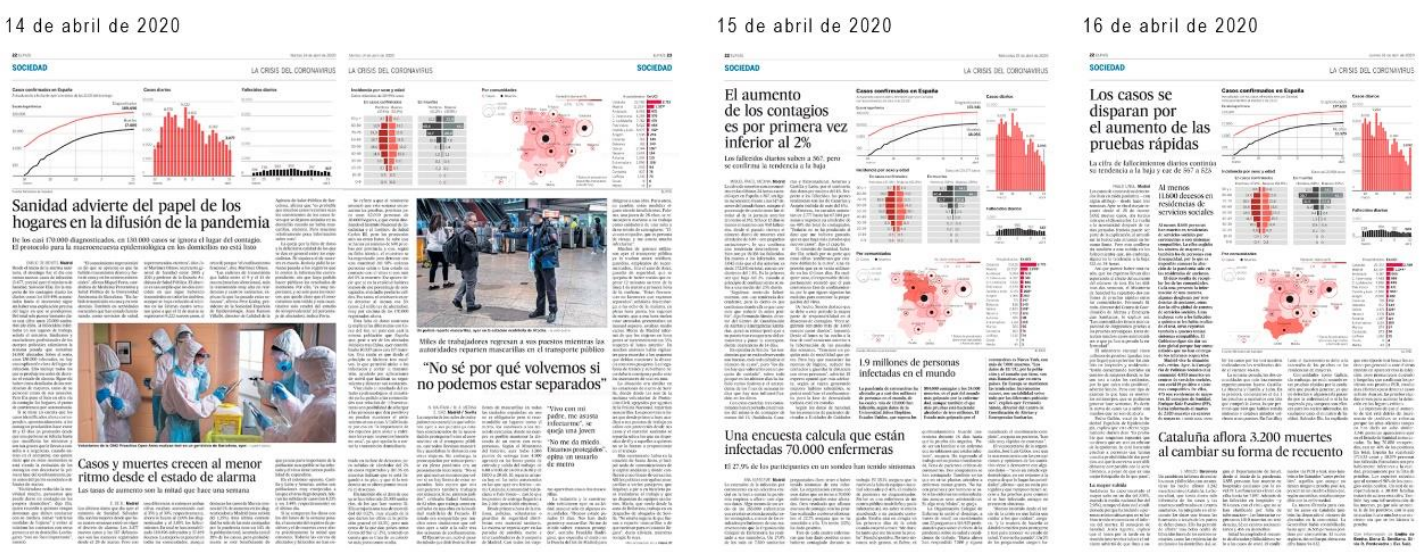

Figura 1. Páginas de El País que marcan la pauta de diseño desde el 14 de abril. Fuente: Diario El País. 
Análisis de contenido de la prensa diaria española sobre el uso de la infografía para informar de la crisis sanitaria de la COVID-19

En El Mundo se establece antes, desde el 13 de marzo. Abre las páginas especiales un cintillo que abarca ambas páginas enfrentadas. La anchura de la barra, el color azul calado por blanco, la tipografía de la sección que denominan Primer plano bajo folio y el icono del coronavirus nos da una idea de la relevancia del especial por su contundencia y del afán de integrar toda la información bajo ese cintillo.

El diseño básico del especial concentra el peso de las infografías en la parte superior de las páginas y se forma un frontón en la parte superior que casi todos los días contiene en primer un mapa de España en la página par y a la derecha, en la impar, un mapamundi que suelen ir acompañados de pequeñas gráficas de barras, líneas, áreas. Es decir, que en la información prima el factor de la cercanía y en segundo lugar la proyección en el mundo. Esta distribución deja una página horizontal que se acrecienta por un perfil o entradilla a todo el ancho de la página. Muy sólido el diseño, excesivamente hierático al principio, con el desarrollo comienza a incorporar siete gráficas que arrancan de la parte baja de la página y su desarrollo recorre el texto con espectacularidad, mientras que en otras tantas ocasiones recurren a un gráfico vertical extra con un ancho de dos o tres columnas y todo el alto de la página a excepción de una vez. En todos los modelos se mantiene la misma gama de los azules y tramas para todos los infográficos que evidencia el modelo estricto que se sigue para este especial.
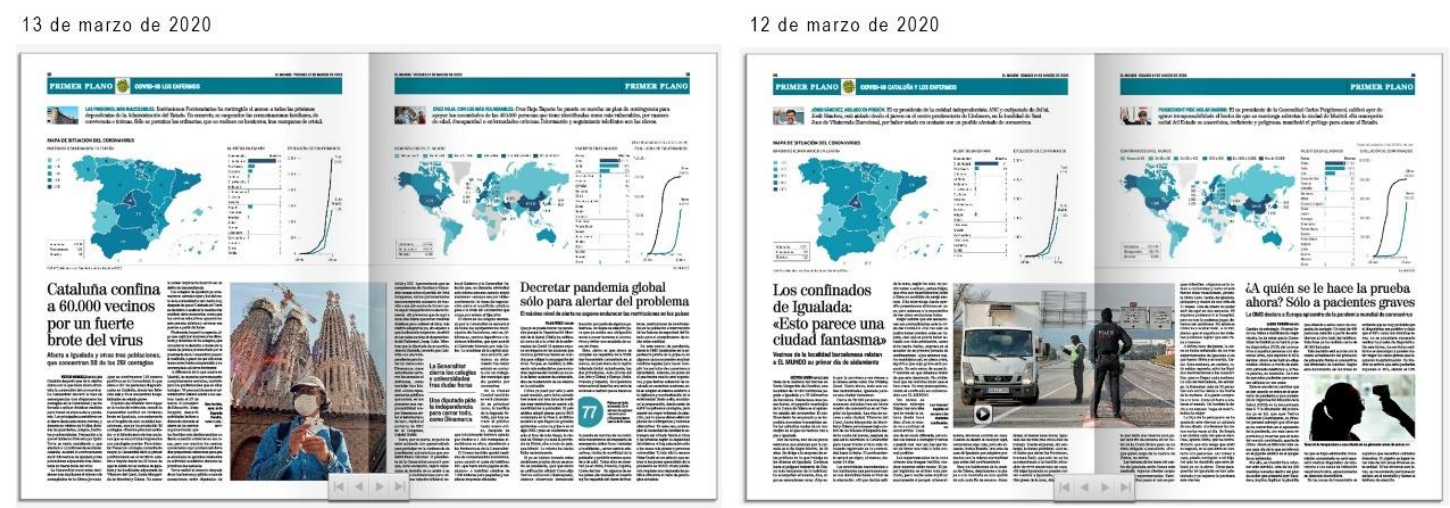

Figura 2. Páginas de El Mundo que consolidan el diseño desde el 13 de marzo. Fuente: Diario El Mundo.

En el caso de La Vanguardia se estandariza el 10 de marzo, y comienza con la continuidad gráfica de la información de la pandemia con un sobrio cintillo de Emergencia sanitaria que alterna su posición y la trama de color que lo caracteriza. Siendo el medio que ostenta el mayor número de infografías durante todo el periodo de estudio, lo cierto es que no tiene comparación con las magníficas páginas de $A B C$ o el diario El Mundo. Si bien comienzan ocupando 4 o las 5 columnas del diario los diez primeros días de marzo con la composición de varias gráficas, mapa de símbolos proporcionales de España y gráfica de línea, enseguida se ve reducido el interés infográfico en este especial. Dos pequeñas gráficas de área a una columna, y en algún caso una, es la norma que impera en esta publicación muy pronto. Tediosas y redundantes durante un mes salvo excepciones de varios gráficos a tres columnas, 
Análisis de contenido de la prensa diaria española sobre el uso de la infografía para informar de la crisis sanitaria de la COVID-19

termina consolidando a dos columnas la gráfica que antes estaba a una. Sorprende el escaso tratamiento infográfico en un medio con una gestión tipográfica de altura.
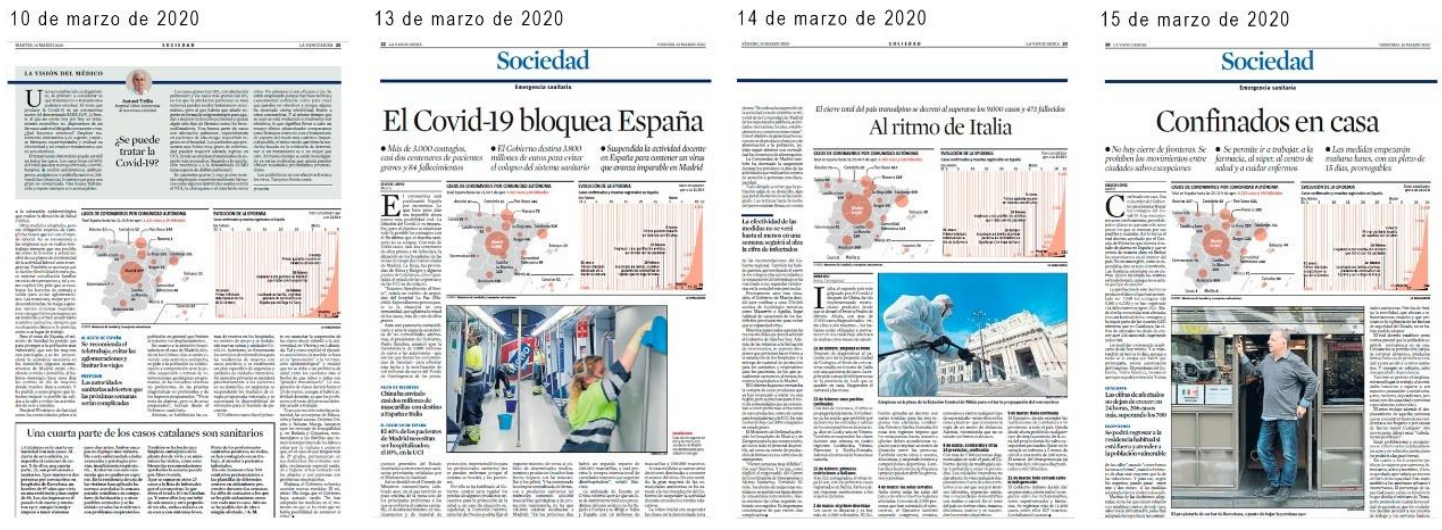

Figura 3. Páginas de La Vanguardia que marcan la pauta de diseño desde el 10 de marzo.

Fuente: Diario La Vanguardia.

En el diario $A B C$ el 27 de marzo se toma la decisión de consolidar el diseño en la sección de sociedad. Abre igualmente con un cintillo por arriba que comienza con el texto Crisis del coronavirus y engatillado especifica el tema. Se caracteriza por la gama de colores calientes con predominio naranja y el rojo, siendo el único caso en el que el color salta al cuerpo de la información con tramas del rojo, tipografías de titulillos también en rojo hasta que el 18 de marzo salta al título a 5 columnas en caja alta: Qué ofrece el gobierno.

El $A B C$ incorpora un elemento iconográfico que representa el virus también en esos tonos y que se utiliza para dar dinamismo a la composición, se convierte en un centro de interés visual que juega con los pesos de la página buscando el equilibrio (el peso de los gráficos se concentra en la parte superior), genera recorridos textuales que dan fluidez y se alterna con la figura completa o secciones de la misma sobre la base de la página. Las formas circulares tienen mucha presencia, bien en gráficos de tarta como esféricos proporcionales, o como recursos circulares de color que albergan información para destacar. El equilibrio de formas es muy interesante cuando hay tanto gráfico de fiebre y barras y se compensa perfectamente con la incorporación de estos elementos circulares. Un trabajo de diseño de la información perfecto en todos los órdenes. 
Análisis de contenido de la prensa diaria española sobre el uso de la infografía para informar de la crisis sanitaria de la COVID-19
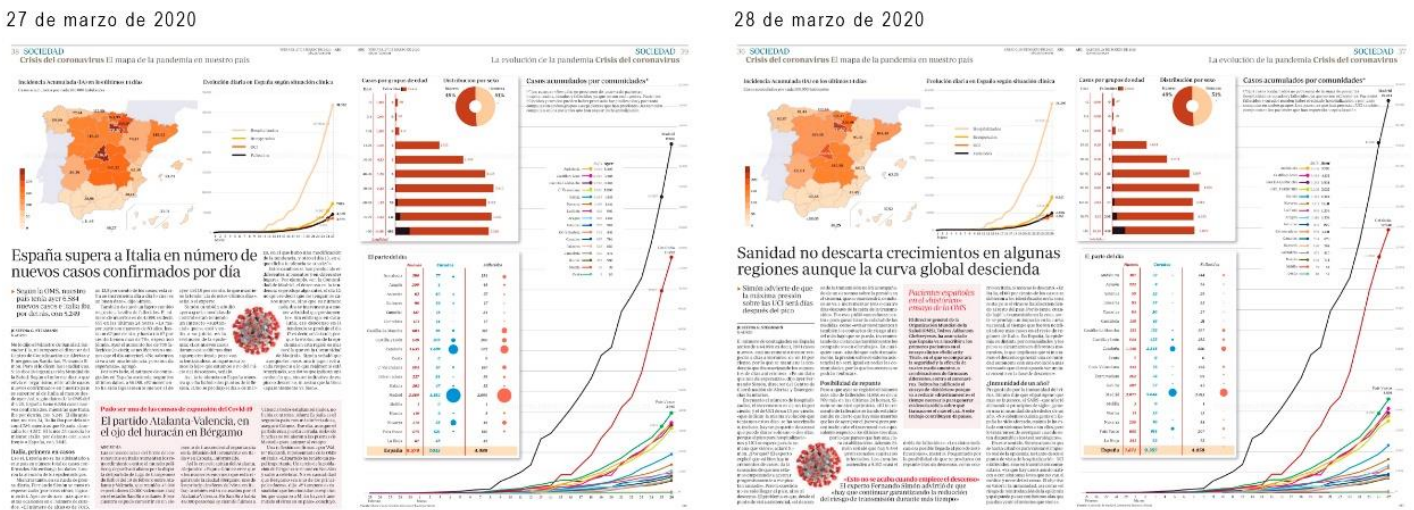

Figura 3. Primeras páginas de $A B C$ donde se aplica el diseño específico a partir del 27 de marzo.

Fuente: Diario ABC.

\section{CONCLUSIONES}

Esta investigación sirve para conocer el uso del género informativo de la infografía durante los primeros meses de la pandemia producida por la covid-19, así como para encontrar patrones de trabajo en la aplicación de la infografía en situaciones excepcionales o de crisis.

Partimos de la hipótesis de que el género periodístico más adecuado para transmitir la información compleja del coronavirus era la infografía y se constata al observar el aumento de infografías de carácter independiente que se publican relativas al tema y que se concentran en los meses de marzo y abril cuando los datos se acumulan en torno a las variables que definen la pandemia, se agudiza la crisis y se difunden para una información más eficaz a una población que demanda informaciones fiables, exactas y rigurosas en un entorno de alarma social.

Estas infografías se caracterizan por la naturaleza de los datos que la justifican. Los periodistas se enfrentan a una gran cantidad y complejidad de los datos así que deben representarse gráficamente para ser comprendidas de manera más rápida y visual. Estos datos también se caracterizan por ser continuos en el tiempo y secuenciales en las representaciones, y se trabaja con las mismas variables en la actualización constante de los datos. La temática sobre el coronavirus que predomina en las infografías es la evolución de las cifras de contagios y fallecidos, relevante en tanto que los datos informan a la población el avance o retroceso de la pandemia y sus representaciones infográficas de los datos fundamentalmente son las gráficas comparativas y los mapas ubicativos con dichas variables.

Las formas de representación de esta información esencial serán fundamentalmente a través de gráficas simples, dominando columnas, línea y áreas, y los mapas representan la información con diferentes códigos ya sean puntos, color o símbolos 
Análisis de contenido de la prensa diaria española sobre el uso de la infografía para informar de la crisis sanitaria de la COVID-19

proporcionales para cumplir con las funciones informativa y ubicativa de la infografía. Durante el periodo de análisis establecido las megainfografías siempre han estado relacionadas con la temática del covid-19, aunque esperábamos que fueran a publicar un grupo más numeroso.

En las infografías sobre la crisis por coronavirus prevalece el factor de la cercanía en los temas, aunque sea una pandemia mundial, se han concentrado en torno a la sección de Sociedad porque afecta a toda en su conjunto y han sido elaboradas en su mayoría por los departamentos de las propias cabeceras. Además, la fuente más consultada para la obtención de datos han sido los organismos públicos. Existe una tendencia mayoritaria a presentar las infografías como elementos informativos independientes, lo que fomenta la idea de que estos elementos se han convertido en un nuevo género periodístico.

La peculiaridad de la situación de crisis, extendida en el tiempo, datos de temática recurrente que se acumulan, información que afecta a la salud, la economía y a todos los campos evidencia la necesidad de crear un estilo infográfico específico y de la puesta en página para informar de los temas del coronavirus con el objetivo de integrar contenidos, actualizarlos de manera rápida, mantenerlos acumulados en el tiempo, representar la concordancia temática así como crear una identidad informativa.

Las cuatro cabeceras del estudio realizan un diseño específico y general al tema del coronavirus, en una fecha temprana de la pandemia y que se extiende mucho más allá de la finalización de la información. Se evidencia la tendencia en todos los diarios a agrupar las informaciones del covid-19 en base al diseño, en la constancia y coherencia en todas sus aplicaciones: sigue el primer principio del diseño de la información, que no es otro que a la misma información se debe aplicar la misma representación. Esto, que se aplica a niveles de título, gamas cromáticas, gráficas, mapas, recursos infográficos y demás, aquí supone un salto de grado, ya que se lleva al conjunto de los elementos de la temática, pero además, trasciende el tiempo y la continuidad en el uso de estos principios alcanza todo el tratamiento infográfico del estudio de la pandemia.

En situaciones de crisis mucho de la aprendido durante este proceso se utilizará para cubrir las necesidades futuras que puedan surgir. Los resultados obtenidos en la investigación son de utilidad en la medida que toda situación informativa compleja de características similares puede repetir este modelo informativo por la eficacia informativa demostrada.

\section{REFERENCIAS}

Abreu Sojo, C. (2002). “¿Es la infografía un género periodístico?”. Revista Latina de Comunicación Social, $51 . \quad$ Recuperado de: http://www.revistalatinacs.org/2002abreujunio5101.htm 
Análisis de contenido de la prensa diaria española sobre el uso de la infografía para informar de la crisis sanitaria de la COVID-19

Aced, E.; Heras, M. R.; Sáiz, C. A. (2017). Código de buenas prácticas en protección de datos para proyectos big data. Recuperado de: https://www.aepd.es/sites/default/files/2019-09/quia-codigo-de-buenas-practicasproyectos-de-big-data.pdf

Alonso, J. (1998). "Grafía. El trabajo en un agencia de prensa especializada en infográficos". Revista Latina de Comunicación Social, agosto, n. 8. Recuperado de: http://www.revistalatinacs.org/a/49inf6.htm

Asociación para la Investigación de Medios de Comunicación (2020). Estudio General de Medios. Primera Ola $2020 . \quad$ Recuperado de: http://reporting.aimc.es/index.html\#/main/diarios

Ben Ali, O. y El Haddadi, A. (2018). "Big Data Visualisation". National School of Applied Sciences Al-Hoceima. Recuperado de: https://www.semanticscholar.org/paper/BigData-Visualization-Ali-Haddadi/96c97a24341c5bab1ac9a4f4e3db2a8628eb54a3

Cairo, A. (2017). "Visualización de datos: una imagen puede valer más que mil números, pero no siempre más que mil palabras". El profesional de la información, 26 (6), 1025-1028. doi: $10.3145 /$ epi.2017.nov.02

Cairo, A. (2012). El arte funcional: una introducción a los gráficos de información y visualización. Berkley: Peachpit Press.

Cairo, A. (2011). El arte funcional. Infografía y visualización de información. Madrid: Alamut. ISBN: 9788498890679

Cairo, A. (2011). "El periodista y los mapas". Blog El País. Recuperado de: https://blogs.elpais.com/periodismo-con-futuro/2011/11/el-periodista-y-losmapas.html

Cleveland, W. S. y McGill, R. (1984). "Graphical Perception: Theory, Experimentation, and Application to the Development of Graphical Methods". Journal of the American Statistical Assosiacion, septiembre, v. 79, n. 387, pp. 531-554. Recuperado de: http://euclid.psych.yorku.ca/www/psy6135/papers/ClevelandMcGill1984.pdf

Comité español de ACNUR (2020). "Cronología del coronavirus: evolución de la pandemia". España: blog de la Agencia de la ONU para los Refugiados Comité español. Recuperado de: https://eacnur.org/blog/cronologia-del-coronavirusevolucion-de-la-pandemia-tc alt45664n o pstn o pst/

Cortizo Álvarez, T. (2007). "Protocolo para la normalización del tratamiento geográfico de la infogramción (TGGI)". Boletín de la A.G.E., noviembre, n. 45, pp. 279-305. Recuperado de: http://age.ieg.csic.es/boletin/45/12-protocolo.pdf 
Análisis de contenido de la prensa diaria española sobre el uso de la infografía para informar de la crisis sanitaria de la COVID-19

Crespo, I. y Garrido, A. (2020). "La pandemia del coronavirus: estrategias de comunicación de crisis". Más poder local, abril, 41, 12-19. Recuperado de: https://dialnet.unirioja.es/servlet/articulo?codigo $=7407214$

Diario El Mundo (s.f.). Libro de estilo del diario El Mundo. Sevilla: Comunicación y proyectos editoriales en contexto. Recuperado de: http://www.masmenos.es/wp-content/uploads/2002/01/librodeestilo elmundo.pdf

Ferreras Rodríguez, E. M. (2016). "El Periodismo de Datos en España”. Estudios sobre el Mensaje Periodístico, 22 (1), 255-272. doi: 10.5209/rev ESMP.2016.v22.n1.52594

Flores Vivar, J. M. y López López, P. J. (2020). "Radiografía del periodismo de datos en las facultades de Comunicación españolas: innovando los estudios de grado en Periodismos". Anàlisis: Quaderns de Comunicació i Cultura, 62, 77-92. doi: $\underline{10.5565 / \text { rev/analisi.3273 }}$

Hernández Lorca, F. J. (2010). "Infografía para acontecimientos excepcionales el accidente de Spanair en los diarios El País y El Mundo". Siranda, 1 (3), 80-92. Recupeado de: https://dialnet.unirioja.es/servlet/articulo?codigo=6441302

Igartua, J. J. (2006). Métodos cuantitativos de investigación en comunicación. Barcelona: Editorial Bosch. ISBN: 9788497902717

Insituto Nacional de Estadística (s.f.). "Dos siglos de gráficos estadísticos. William Playfair". Recuperado de: https://www.ine.es/expo graficos2010/expogra autor2.htm

Krippendorff, K. (1990). Metodología de análisis de contenido. Teoría y práctica. Barcelona: Paidós Ibérica. ISBN: 9788475096278

Leturia, E. (1998). “¿Qué es infografía?” Revista Latina de Comunicación Social, n. 4. Recuperado de: http://www.revistalatinacs.org/z8/r4el.htm

Llanera, K. (2020). Los problemas de usar datos del siglo pasado para una pandemia del siglo XXI. Recuperado de: https://elpais.com/sociedad/crisis-delcoronavirus/2020-06-20/los-problemas-de-usar-datos-del-siglo-pasado-para-unapandemia-del-siglo-xxi.html

López Del Ramo, J. y Humanes, M. L. (2016). "Análisis de contenido de la representación fotográfica de la crisis de los refugiados sirios y su incidencia en el framing visual". Scire, 22 (2), 87-97. Recuperado de: https://www.academia.edu/29737143/An\%C3\%A1lisis de contenido de la represen taci\%C3\%B3n fotogr\%C3\%A1fica de la crisis de los refugiados sirios y su inci dencia en el framing visual?auto=download 
Análisis de contenido de la prensa diaria española sobre el uso de la infografía para informar de la crisis sanitaria de la COVID-19

Montez Vozmediano, M. y García Jiménez, A. (2015). "El color en las publicaciones periódicas. Funcionalidades en las revistas femeninas de alta gama". adComunica, n. 10, 117-134. doi: http://dx.doi.org/10.6035/2174-0992.2015.10.8

Ñaupas Paitán, H.; Mejía Mejía, E.; Novoa Ramírez, E. y Villagómez Paucar, A. (2014). Metodología de la investigación cuantitativa-cualitativa y redacción de la tesis. Colombia: Ediciones la U. ISBN: 9789587621884

Organización Mundial de la Salud (2020). Covid-19: cronología de la actuación de la OMS. Recuperado de: https://www.who.int/es/news-room/detail/27-04-2020-whotimeline---covid-19

Organización Mundial de la Salud (2020). Preguntas y respuestas sobre la enfermedad por coronavirus (Covid-19). Recuperado de: https://www.who.int/es/emergencies/diseases/novel-coronavirus-2019/advice-forpublic/q-a-coronaviruses

Peltzer, G. (1991). Periodismo iconográfico. Madrid: Ediciones Rialp. ISBN: 97554 32128080

RTVE (2020). El mapa del coronavirus en España: 27.125 muertos y más de 239.000 contagiados. Recuperado de: https://www.rtve.es/noticias/20200531/mapa-delcoronavirus-espana/2004681.shtml

Salvat Martinrey, G. (2018). "De la infografía a la visualización de datos. Impacto del Big Data en el diseño de la información". Revista Internacional de Cultura Visual, 5(1), 35- 41. doi: 10.37467/gka-revvisual.v5.1822

Salvat Martinrey, G. (2013). "La libertad de la información tras la explosión del Big Data". En: Gómez-Escalonilla, Gloria. La libertad de la información en el siglo XXI. España: Fragua, pp. 131-141. ISBN: 978847074717 5. Recuperado de: https://dialnet.unirioja.es/servlet/articulo?codigo $=7219303$

Salvat Martinrey, G. (2003). "La última especialización: el redactor gráfico". En: De Ramón-Carrión, Ramón. 10 lecciones de Periodismo Especializado. Madrid: Fragua, pp. 193-211. ISBN: $84 \quad 7074 \quad 140$ 3. Recuperado de: https://www.researchgate.net/publication/307513373 Ultima especializacion el reda ctor grafico

Serra, J. M. (1998). "La irrupción del infografismo en España". Revista Latina de Comunicación Social, $11 . \quad$ Recuperado de: http://www.revistalatinacs.org/a/10Ainfo9.htm

Subiela Hernández, B. J. (2017). "Diseño de la información y progreso social: prospectiva, perspectiva y retos". Profesional de la Información, 26(6), 1019-1024. doi: $10.3145 /$ epi.2017.nov.01 
Análisis de contenido de la prensa diaria española sobre el uso de la infografía para informar de la crisis sanitaria de la COVID-19

Tascón, M. (2011). Malofiej 18. España: Index Book. ISBN: 9788492643912

Valero Sancho, J. L. (2008). "Tipología del grafismo informativo. Estudios sobre el Mensaje Periodístico, 14, 631-648. Recuperado de: http://webs.ucm.es/info/emp/Numer 14/Sum/4-22.pdf

Valero Sancho, J. L. (2000). "La infografía de prensa". Ámbitos, (3-4), 123-131. Recuperado de: https://ddd.uab.cat/pub/artpub/1999/116125/ambitos a1999-2000n34p123.pdf

\section{AUTORES}

\section{Guiomar Salvat Martinrey}

Profa. Titular de la URJC. Departamento de Comunicación y Sociología de la Facultad de Comunicación. Doctora en Ciencias de la Información y licenciada en Periodismo por la Universidad Complutense de Madrid. Ha investigado en dos proyectos del Ministerio de Educación y Ciencia sobre las Nuevas Tecnologías de la Información, otro de la Comunidad de Madrid y colaborado en varios proyectos internacionales. Ha realizado estancias de investigación y docencia en Heerlen (Países Bajos), Múnich (Alemania) y Valdivia (Chile). Autora de libros entre los que destacan "La experiencia digital en presente continuo", "La revolución digital y la sociedad de la información" y "Tras el ensayo digital" y capítulos de libro como "La última especialización: el redactor gráfico" o "La libertad de información tras la explosión del Big Data", así como de artículos en revistas especializadas de alto impacto como Latina de Comunicación Social, Telos, Estudios sobre el mensaje periodístico, Análisi, entre otras.

Orcid ID: https://orcid.org/0000-0001-6402-259X

Google Scholar: https://scholar.google.es/citations?user=xKUomVcAAAAJ\&hl=es

ResearchID: https://www.researchgate.net/profile/Guiomar Salvat Martinrey/research

Academia edu: https://uric.academia.edu/GuiomarSalvat

\section{Sara Aranda Martínez}

Periodista y comunicadora audiovisual. Especialista en información internacional. Redactora de información internacional y política nacional para el medio La Hora Digital, así como redactora de contenidos culturales para la revista online Culturamas. Community y Content Manager de la Misión Diplomática de Palestina en Madrid. Redactora y maquetadora para las revistas de televisión, Supertele, TP y Telenovela del grupo Hearst.

Orcid ID: https://orcid.org/0000-0001-8078-6135

Google Scholar: https://scholar.google.com/citations?user=68pAl-EAAAAJ\&hl=es

Academia edu: https://urjc.academia.edu/SaraAranda 